\title{
MULTICRITERIA EVALUATION OF HARBOR MARKETING STRATEGIES USING ANALYTIC HIERARCHY PROCESS : AN EXAMPLE OF THE KEELUNG PORT IN TAIWAN
}

\author{
Junn-Yuan TENG ${ }^{a}$, Wen-Chih HUANG ${ }^{b}$, Mei-Fen CHEN ${ }^{b}$, Hsu-Hsi Chang ${ }^{c}$ \\ a. Dept. of Industrial Management, Huafan University \\ Shihdin Hsiang Taipei County, 223, Taiwan \\ b. Dept. of Harbor and River Engineering, National Taiwan Ocean University \\ P. O. Box 7-107 Keelung, 202, Taiwan. \\ c. China Engineering Consultants INC. \\ 6FL. 280 CHUNG-HSIAO E. Road Sec 4 Taipei, Taiwan \\ jyteng@huafan.hfu.edu.tw/.Huangwc@ntou66.ntou.edu.tw/ sschang@ceci.org.tw
}

\begin{abstract}
The importance of marketing for public transportation has received increasing attention in the twenty years. Recently, port management also can be an important marketing decision area. A port agency has to consider the best means of making its facilities available to the carriers and the shippers. Marketing management of harbor is the analysis, evaluation, planning, implementation, and control of marketing strategies designed to bring about desired benefits. In this process, marketing strategies analysis and evaluation are the most important stages for marketing management.

The Analytic Hierarchy Process (AHP) is ideally suited to the evaluation of a harbor's marketing strategies. From the view point of the international port management, the activities of the harbor should be extended to the logistic and infrastructure investment. In the proposed evaluation system, five levels as durations, scenarios, objectives, activities, and strategies are considered. Finally, a case study of the Keelung port is presented to illustrate the proposed evaluation system.
\end{abstract}

\section{Introduction}

This study paper according to the marketing concepts to show the whole activity analysis based on the needs and suggestion of customers. With the marketing experiences of the neighborhood harbors, it also analyzes the choices and tab top of Keelung Port of Taiwan to provide the plan of marketing strategies. In the past, port administration of Taiwan is balsed on the system of public enterprise so the attitude toward its management is always passive with waiting for the automatic coming of the customers. However, the competition of modern port management environment is increasing intense. Besides, the multi-transportation is prevailing. Therefore, so called geography location and large inland cannot be the good tool for supporting port competition. Gradually, the port marketing shows its importance more under the situation of the increasing port businesses. While, the marketing techniques turn into the passive marketing way of actively broadening the quantity of customers instead of waiting for the customers in the past. Moreover, there is a close relationship between the development, management, and profits of the port and the users ( the customers), especially the ship-owners and carriers. In a word, the port marketing stresses not only the home market and information but also the collection and control of messages of the trading countries, such as the ports, goods, and so on.

International harbors are industries which provide a large amount of ship supply, goods loading and unloading or passengers, so being guick, safety, convenience, and economization are necessary terms and function for harbor industries. So how to show themselves with the activity of marketing is an important key in increasing competitive harbor markets. American managerial expert, Peter F. Drucker, used to make it clear of the relationship between marketing and industries, "The industry is an organization which succeeds through production sales or providing a service." Namely, an organization with little marketing cannot be called as an industry. He thinks that marketing which is a central intermediary of the whole industries treats the whole industries through the viewpoint of the result of industries- the viewpoint of customers. Therefore, the careful and resporisible attitude toward marketing must be guided through all departments of industries. The international harbor, a transportation service industry, is especially more important to the marketing plan of tactical harbors. 
The study stresses the application of harbor marketing strategies to the plan and management of harbors to make hierarchy analysis for the best harbor marketing strategy.

\section{The Analytic Hierarchy Process}

The method of analysis:

Systematize the evaluation strategy with hierarchy and adopt the judgement of the experts to compare the paired elements of each hierarchy for the concrete result with common sense. According to the result of the judgement of the experts, apply the theory of AHP to getting the evaluation strategy.

To utilize the technique, the approach is based on three major components:

(1)Constructing the hierarchical structure: AHP start by decomposing a complex problem into a hierarchy; each level consists of a few manageable elements and each element is, in turn,decomposed into another set of elements. The process continues down to the most specific elements of the problem, typically the specific courses of action considered, which are represented at the lowest level of the hierarchy. Consider, for example, the simple 5 level hierarchy of environmental scenarios, objectives, and courses of action. Such a hierarchy, as illustrated in Figure 1, can aid management in identifying their relevant objectives and forces them to explicate the environmental scenarios most likely to affect their port decisions and most likely to be creative in generating specific courses of action. For example, overall goals, duration, scenarios, objectives, activity and Marketing strategy.

(2)Collecting the data of pairwise comparisons: A measurement methodology is used to establish priorities among the elements within each stratum of the hierarchy. A measurement theory to establish the priorities of the hierarchy and the consistency of the judgmental data provided by the group of respondent.

(3)Determining the priorities. The basic premise of the Analytic Hierarchy Process is that measurement evolves out of comparisons, particularly pairwise aomparisons. Let us suppose that we have $n$ objects $A_{1} \ldots . A_{n}$ whose vector of corresponding weights $w=\left(w_{1}, \ldots, w_{n}\right)$ is know. Let us form the matrix of pairwise comparisons of weights

\section{The Hierarchical Struture of Harbor Marketing}

\section{A.Constructing the structure of harbor marketing}

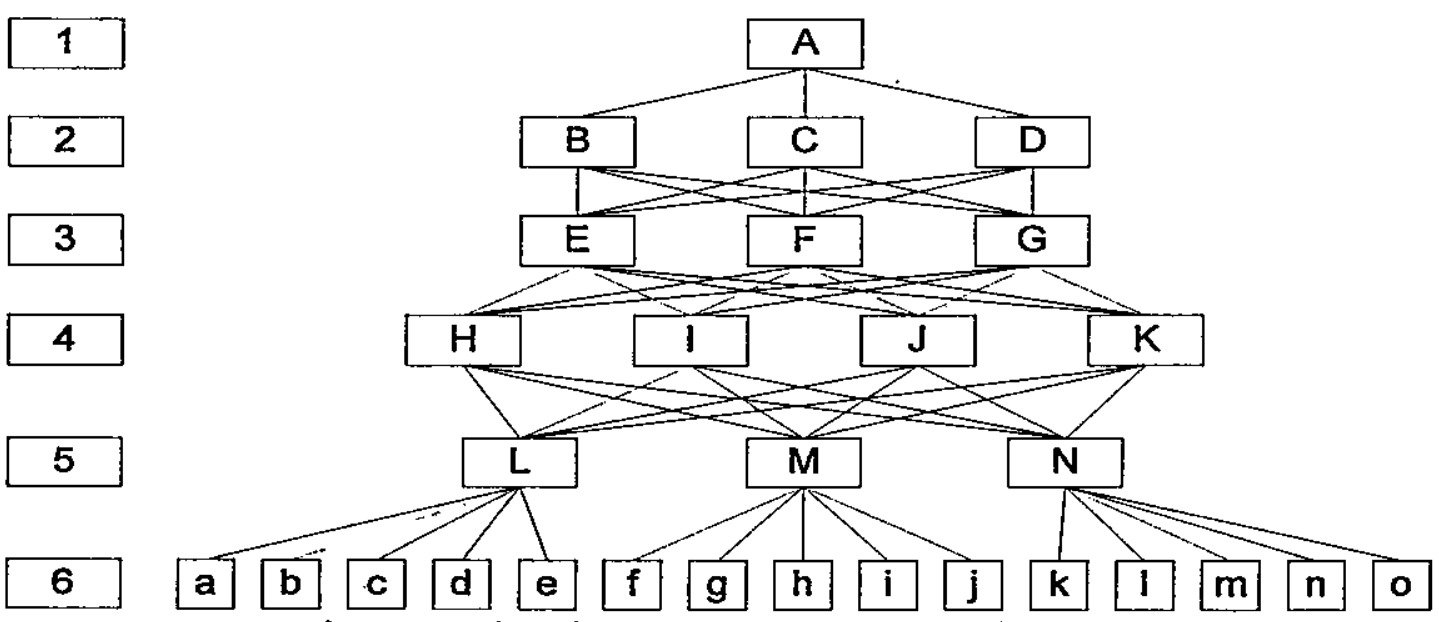

Figure 1: A Hierarchy Structure of Harbor Marketing Strategy

1.Overall goal A.The Well-Being of the harbor (1.000)

2.Durations B.the short term (0.286) C.the middle term (0.574) D.the long term $(0.140)$

3.Scenarios F.optimism(0.286) G.ordinary(0.449) H.pessimistic(0.264) 
4.Objectives l.improving the efficiency of service (0.313) J. appealing the berthing of ship (0.424)

K.appealing the investment $(0.185)$ L.combining the tourism $(0.078)$

5.Activities harbor service (0.509) M.customers/ markets (0.262) N.distribution(0.229)

\section{Marketing strategies}

(1.) (a) improving service quality of harbor management( $(0.145)$ (b) improving the system of the people who divert water and the assigning tugboat $(0.083)$ (c) improving the efficiency of loading and unloading(0.205) (d) establishing the service system of ship berth traffic $(0.046)$ (e) increasing the flight and well managing the schedule of flight(0.029)

(2.) (f) industrializing the harbor management $(0.067)$ (g) establishing the national trade center $(0.018)$ (h) planning the playing and business area(0.029) (i) decreasing the harbor expense $(0.126)(\mathrm{j})$ developing the tourism of sea and land and blue freeway $(0.022)$

(3.) (k) simplifying the management of customs $(0.101)$ (1) informative transfer process $(0.050) \quad$ (m) improving the system of transportation for exterior $(0.030)$ ( $n$ ) setting up the harbor flow area(0.021) (o) establishing the check area in the CY container lot $(0.028)$.

The study applies the theory structure of Analytic Hierarchy Process (AHP) and the characteristic of the mark to analysis based on the characteristic of the multiple goals and the practicable mark of marketing strategy analysis. The hierarchy includes the overall goal, the durations, the scenarios, the objectives, the activity, the marketing strategy, etc.

(A)The multi-criteria analysis of harbor marketing

Marketing management of harbor is the analysis, evaluation, planning, implementation, and control of marketing strategies designed to bring about desired benefits. In the proposed evaluation system, five levels as duration, scenarios, objectives, activities, and strategies are considered.

(B)The analysis of example of marketing values of Keelung Port

According to the evaluation target of the marketing strategy of Keelung Port (Figure1), the evaluation methods of the marketing strategy of Keelung Port are illustrated as follows:

a. Processing the evaluation of the marketing strategy of Keelung Port under each principle of evaluation.

b. Try to deal with Those concretely quantifiable principles with quantifiable information.

c. Those concretely non-quantifiable principles are judged by the experts with their profession skills, mark with $1 \sim 5$ and then get the average value.

d. Turn the capital principle into profit principle to make the evaluation in the same direction.

e. Standardize the marketing strategy of Keelung Port under each principle to make the evaluation with the same level.

B.An example of Keelung Port

(A) The interior and exterior environment analysis of the Keelung Port

How do we make the evaluation system of marketing strategies for the Keelung Port in the north of Taiwan? The study will research the advantage, disadvantage, opportunities and threat of the management of the Keelung Port to provide the marketing strategies of the Keelung Port.

Because of the currently three ports of Keelung Port, Suao Port, and Danshei Port in the north of Taiwan (Suao Port, and Danshei Port are the assistant port of Keelung Port), each port should meet needs of its inland and give different development and function based on the viewpoints of the whole efficiently use, and make the best use of the limited harbor resources according to the geography characteristics. Before choosing the goal market of the Keelung Port, we should first understand the development goal of Suao Port, and Danshei Port, and then evaluate the Keelung Port.

According to the report of "the whole plan and future development of Danshei Port" and " the whole plan and future development of Suao Port", the development goal of Suao Port and Danshei Port are suggested as follows:

a. the development goal of Danshei Port

(a) Put the goal of the policy of "eastern sands transported in the north" into practice 
(b) Loading the transferring quantity of goods of Keelung Port

(c) Loading the increasing quantity of containers of northern area

(d) Providing the passage of a large amount of import of northern area

(e) Loading the inland flow of traffic

(f) Integrating the plan of the seashore use as possible

(g) Reserving the space of the establishment of the center of highly valued flows of goods

b. the development goal of Suao Port

(a) Meeting the needs of the shipment of cement and oily production around Taiwan

(b) Satisfying the needs of the import of east- northern Taiwan and transferring the goods of Keelung Port

(c) Preparing the chance of direct voyage of import and export between Taiwan and China

(B) The classification of related evaluation report of marketing strategy

The management activity is classified into three: the harbor service, the customers/ the market and the harbor flows, each including five marketing strategies, totally fifteen marketing strategies as follows: improving the service quality of the harbor management, increasing the efficiency of loading and unloading, providing the traffic service of harbor (VTS), increasing the flight, well managing the schedule of flight, industrializing the harbor management, decreasing the harbor expense, establishing the national trade center, planning the playing and business area, developing the tourism of sea and land and blue freeway, simplifying the management of customs, informative transfer process, improving the system of transportation for exterior, setting up the harbor flow area and establishing the check area in the CY container lot.

\section{Evaluation of Harbor Marketing Strategies}

In the design of questionnaire, four elements should be considered as follows:

(A) The comparison of elements and principles.

(B) The measurement of each harbor strategy under each principle.

a. The quantifiable parts use the related statistical information as possible.

b. The non- quantifiable parts considered as the principle beyond above items are subjectively evaluated by the experts and scholars with the professional knowledge and experiences.

(C) Providing the detailed description of the evaluation principle and the chart of hierarchy structure.

(D) Providing the description of each harbor background.

The judgment of the importance of harbor marketing strategy and the strategy evaluation of the harbor under the level of the non-quantifiable are obtained with the method of questionnaire. The questionnaires use purpose sampling to mainly research the experts and scholars and secondarily the carry businessmen. As for the experts and scholars, they are divided into two parts to discuss with their ability of harbor management.

Through the appendix description of questionnaire, the examinee will understand the content and fill in correctly. Besides, the questionnaire will be fixed with the result of pretest of the home flight businessmen to make sure of the practicality of recycling information of the questionnaire.

\section{Conclusions}

A. Emphasize the coming of port marketing age

In the past, the management of Taiwan international ports tends to sales orientation and those ports put themselves into the shoes of Bureau of Port Affair to sale the original production to customers. However, the age of customers who highly ask for needs has come and the competition of port market has been increasing intense, so the management should turn sales orientation into marketing orientation. So called marketing orientation emphasizes the needs of customers to promote the port competition and create resources with the principle of the profit and satisfaction of positively creating customers. Namely, the customers will stay and even consider Taiwan as the important 
base if they can bring in profits from Taiwan's international ports. Naturally, much more resources will be brought into Taiwan ports.

B. Both the interior marketing and the exterior marketing are important.

All the members of Bureau of Port Affair should participate in the port marketing. To do the exterior port marketing well, the correct marketing ideas should be first rooted into the hearts of members and then the members will service customers sincerely.

Therefore, the training of education, interior relation, awards, and well- behaved directors are very important to the interior marketing of Bureau of Port Affair.

C. The importance of customer satisfaction

The port management belongs to the transportation service business. Basically, the great difference between service marketing and production marketing lies in the "members". So services with different providers or with different time and location will make different effect. Besides, service is dependent and can not store; hence, service emphasizes the satisfaction of the whole process. Truly, the customer satisfaction (CS) is very important. So called CS means that customers who purchase the production or receive service will meet their needs and feel that the productions are coincident with their expectation and even better than their expectation; besides, they are satisfied with the productions and services.

D. The importance of industrial image of Bureau of Port Affair

Owing to the increasing competitive port industries, the key to winning port industries in the future is to create a good image except for good activities( for example: ports, scenarios, etc.) and marketing (for example: lower expenses, etc.). The image is the key to win because activities and marketing are necessary terms, not competitive advantages. Only combining with activities, marketing, and image can Taiwan ports win in the port markets of the future. Therefore, it is very important to introduce corporate identity system(CIS).

E. Port marketing is a long -term job

(A) The study is the first step of promoting Taiwan Port marketing. The related institutes should devote themselves to the prospect of the development of Taiwan port marketing.

(B) The effect of port marketing is clearly seen in short terms for it is a long term job. Each port should keep on the development of port marketing to promote the image and fame of ports.

F. According to effective questionnaire filled by fifteen professors and scholars and AHP computer program software, the former three numbers of Weight of criteria and final score of Marketing strategy are to increase the efficiency of loading and unloading $(0.205)$, improve the service quality of harbor management $(0.145)$, and decrease the harbor expense $(0.126)$. Another ones are to simplify the custom process (0.101), improve the system of people who divert water and barge assignation (0.083), industrialize harbor management $(0.067)$, establish information of distribution process $(0.050)$, set up service system of harbor transportation VTS $(0.046)$, improve intertransportation system $(0.030)$, increase the flight and promote schedule management $(0.029)$, plan playing and commercial area $(0.029)$, establish custom checking area in CY cabinet $(0.028)$, develop seashore tourism and blue highway (0.022), establish harbor garden of goods flow (0.021), and establish international trading center $(0.018)$.

\section{References}

Wind,Y. and Saaty, T.L.(1980) "Marketing Applications of the Analytic Hierarchy Process $\cdot$,Management Science, Vol.26, No.7.

Ni, H. S.(1995) "The Research of Port Competitive Strategy of Asian-Pacific Sea Transportation center.," The Research of the Competition and Efficiency of International Ports in Asia.

Tre, Y. S., (1989)"The Application of Marketing Management to Port Plan and Management." The Second Annual Conference of Whole Port Plan, Taiwan Port Technique Graduate Institute of Transportation Bureau..

Rol, W. K., Tshan, Y. M., and Huang, C.S. (1995)" Industrial Customer Satisfaction- the Double -Win Tactics Based on Customers". 
Won, K. T. (1993)"The Winning Strategy of Cl"..

Chen, S.(1993)"Re-establishing the industrial image",.

Port Technique Graduate Institute(1996)"The Whole Plan and future development of Keelung Port, Taichung Port, Kaohsiung Port, and Hua-Leim Port".

Philip Kotler(1988)"The Concrete Theory of Marketing". University.

(1997)"The Practice of Marketing". Marketing Research Studio of Japanese Industry 